\title{
DISPONIBILIDADE DE NÍQUEL EM SOLO TRATADO COM LODO DE ESGOTO E CULTIVADO COM SORGO $\left({ }^{1}\right)$
}

\author{
MARCOS DONIZETI REVOREDO $\left({ }^{2}\right)$; WANDERLEY JOSÉ DE MELO $\left({ }^{2 *}\right)$
}

\begin{abstract}
RESUMO
A presença do metal pesado níquel no lodo de esgoto pode se constituir em entrave para sua aplicação em solos agrícolas. Nesse contexto, o presente trabalho teve como objetivo avaliar o efeito da aplicação do lodo de esgoto contaminado com doses crescentes de níquel, em um solo, sobre a disponibilidade e a absorção desse metal pelas plantas de sorgo. O experimento foi desenvolvido em casa de vegetação, em vasos, usando Latossolo Vermelho distrófico. As amostras de solo foram coletadas aos 0 e 128 dias após a instalação do experimento. O delineamento utilizado foi o inteiramente casualizado, com cinco tratamentos (4 doses de níquel no lodo de esgoto e 1 tratamento testemunha, sem adição de lodo de esgoto e com fertilização mineral) em quatro repetições. A aplicação de lodo de esgoto contaminado com doses crescentes de níquel resultou em aumentos proporcionais nos teores "total" e disponíveis de níquel no solo. Os extratores Mehlich-1 e Mehlich-3 extraíram os maiores teores de níquel do solo. O Mehlich-3 foi o extrator que obteve a maior correlação com as quantidades de níquel presentes nas plantas de sorgo. A partir do aumento dos teores de níquel no solo, ocorreu também aumento na absorção desse metal pesado, de 39,93; 101,16; 152,58 e 171,38 \%, pelas plantas de sorgo.
\end{abstract}

Palavras-chave: Sorghum bicolor L., metal pesado, biossólido, contaminação e extrator.

\section{ABSTRACT \\ AVAILABILITY OF NICKEL IN SOIL TREATED WITH SEWAGE SLUDGE AND CULTIVATED WITH SORGHUM}

The presence of the heavy metal nickel in plants growing in soils treated with sewage sludge can be a restraining factor for using this waste in agriculture. The aim of this paper was to evaluate nickel availability and absorption by sorghum plants in soil treated with sewage sludge contaminated with increasing doses of nickel. The experiment was carried out in a greenhouse, in pots, using samples of a Typic Haplustox. Soil samples were collected 0 and 128 days after the experiment was established. The statistical design adopted was completely randomized, with five treatments (four doses of nickel in the sewage sludge and one control without sewage sludge and only with mineral manure) with four replicates. The application of sewage sludge contaminated with increasing doses of nickel resulted in proportional increasing contents of "total" and available nickel in soil. Mehlich-1 and Mehlich-3 extracted the highest concentrations of nickel in this soil. Mehlich-3 was the extractant that obtained the highest correlation with the concentrations of nickel in sorghum plants. With the increasing concentrations of nickel in the soil occurred an increase in the absorption of this heavy metal by $39.93 ; 101.16 ; 152.58$ e $171.38 \%$, by sorghum plants.

Key words: Sorghum bicolor L., heavy metal, biosolid, contamination and extractor.

( $\left.{ }^{1}\right)$ Parte da Dissertação de Mestrado do primeiro autor apresentada à FCAV/UNESP - Jaboticabal (SP). Recebido para publicação em 7 de novembro de 2005 e aceito em 9 de agosto de 2006.

$\left(^{2}\right)$ Departamento de Tecnologia, Faculdade de Ciências Agrárias e Veterinárias/UNESP, Via de Acesso Prof. Paulo Donato Castellane, s/n. ${ }^{\circ}$ 14884-900 Jaboticabal (SP). E-mail: wjmelo@fcav.unesp.br; revoredo@fcav.unesp.br. *Autor para correspondência. 


\section{INTRODUÇÃO}

O comportamento do níquel no solo, principalmente quando adicionado na forma de lodo de esgoto, ainda é bem pouco conhecido. Apenas mais recentemente trabalhos vêm sendo desenvolvidos com este objetivo, principalmente tendo em vista o elevado teor do metal encontrado em lodos de esgoto obtidos em regiões metropolitanas (REVOREDO, 2005).

Embora ainda exista a necessidade de muitos estudos acerca deste assunto, PAGE et al. (1987) verificaram em trabalho de revisão, informações importantes sobre o comportamento, no sistema soloplanta, do níquel adicionado via lodo de esgoto. De acordo com esses autores, dois aspectos são relevantes: o primeiro é que o lodo desempenha, simultaneamente, papel de fonte e agente imobilizador desse metal no solo; o segundo é que a absorção de níquel pelas plantas decorrente das doses desse resíduo tem apresentado diferentes tipos de resposta incluindo comportamentos lineares, efeitos negativos ou simplesmente inexistentes.

Existem diversos trabalhos que têm demonstrado que a aplicação de lodo de esgoto promove o aumento da concentração de metais no solo (Mulchi et al., 1991; Hooda e Alloway, 1993). A contaminação causada por metais pesados nos solos tratados com lodo de esgoto tem sido avaliada pela concentração total desses metais no solo. No entanto, o fato do metal pesado estar presente no solo não significa que esteja em forma prontamente assimilável pelas plantas, podendo permanecer por longos períodos sem ser absorvido em quantidades tóxicas (Simonete e Kiehl, 2002).

Na literatura, é possível verificar extratores, para estudar a disponibilidade de níquel em áreas que recebem lodo de esgoto, podendo destacar o ligante orgânico ou complexante DTPA e as soluções ácidas HCI 0,1 mol L-1 e Mehlich-3 (Bertoncini, 1997; Anjos, 1999; Oliveira, 2000). O uso de agentes complexantes decorre da sua habilidade de deslocar metais ligados a radicais orgânicos e carbonatos, extraindo com facilidade as formas lábeis dos metais, sem dissolver as não lábeis (ABREU et al., 1997). O extrator DTPA a pH 7,3, foi proposto por LindSAY e Norvell (1978), para determinação de $\mathrm{Cu}, \mathrm{Zn}, \mathrm{Fe}$ e $\mathrm{Mn}$ em solos calcários e em solos com valores de $\mathrm{pH}$ próximos à neutralidade. Atualmente, os laboratórios de análise de solo do Estado de São Paulo têm utilizado esse extrator como método oficial para determinação de Fe, $\mathrm{Cu}, \mathrm{Mn}$ e Zn (CANTARella et al., 1995). Em diversos trabalhos, tal solução também tem sido utilizada para determinar outros metais como $\mathrm{Cd}, \mathrm{Ni}$ e $\mathrm{Pb}$ em solos (Abreu et al., 1995; Oliveira, 2000).
O níquel pode expressar seu potencial poluente diretamente nos organismos do solo, pela disponibilidade às plantas em níveis fitotóxicos, além da possibilidade de transferência para a cadeia alimentar através das próprias plantas ou pela contaminação das águas de superfície e subsuperfície (ChANG et al., 1987).

Dessa maneira, o objetivo deste trabalho foi avaliar, em casa de vegetação, o efeito da aplicação do lodo de esgoto contaminado com doses crescentes de níquel, no solo, sobre a disponibilidade e a absorção desse metal pelas plantas de sorgo.

\section{MATERIAL E MÉTODOS}

O experimento foi instalado e desenvolvido em casa de vegetação dotada de controle de temperatura $\left(28 \pm 5^{\circ} \mathrm{C}\right)$ na Faculdade de Ciências Agrárias e Veterinárias (FCAV) da UNESP, em Jaboticabal (SP), localizada a uma altitude de $610 \mathrm{~m}$ e com as coordenadas geográficas $21^{\circ} 15^{\prime} 22^{\prime \prime} \mathrm{S}$ e $48^{\circ} 15^{\prime} 18^{\prime \prime} \mathrm{O}$.

Utilizou-se Latossolo Vermelho Distrófico, coletado em área mantida sem cultivo na Fazenda de Ensino e Pesquisa da FCAV, cujos atributos químicos foram determinados de acordo com os métodos descritos em RAIJ et al. (1987), a saber: $\mathrm{pH}\left(\mathrm{CaCl}_{2}\right)=$ 5,$0 ; \mathrm{P}($ resina $)=3 \mathrm{mg} \mathrm{dm}^{-3} ;$ matéria orgânica $=8 \mathrm{~g} \mathrm{dm}^{-}$ 3; $\mathrm{K}=0,7 ; \mathrm{Ca}=12 ; \mathrm{Mg}=4 ; \mathrm{H}+\mathrm{Al}=18 ; \mathrm{SB}=17 ; \mathrm{T}=35$ $\mathrm{mmol}_{\mathrm{c}} \mathrm{dm}^{-3} ; \mathrm{V}=48 \%$; e Níquel $=5,66 \mathrm{mg} \mathrm{kg}^{-1}$ (UsEPA, 1986). A amostra utilizada foi retirada da camada de $0-20 \mathrm{~cm}$, seca ao ar e passada em peneira com $5 \mathrm{~mm}$ de diâmetro. O solo de cada vaso foi incubado no ambiente da casa de vegetação com calcário dolomítico $(9,3 \mathrm{~kg}$ de solo $+2,6 \mathrm{~g}$ de calcário) por 30 dias em sacos de polietileno, com umidade em $70 \%$ da capacidade de retenção, para elevar a saturação por bases a 70\% (RAIJ et al., 1997). Passado o período de incubação, o solo de cada saco foi deixado secar ao ar, destorroado e peneirado.

O lodo de esgoto foi obtido na Estação de Tratamento de Esgotos (ETE) da Companhia de Saneamento Básico do Estado de São Paulo (SABESP) em Barueri, Região Metropolitana de São Paulo, SP, apresentando a seguinte composição química: Corgânico $=252 ; \mathrm{N}($ kjeldahl $)=41 ; \mathrm{P}=20 ; \mathrm{K}=2 ; \mathrm{S}=4 ; \mathrm{Ca}=$ $17 \mathrm{e} \mathrm{Mg}=26\left(\mathrm{em} \mathrm{g} \mathrm{kg}^{-1}\right) ; \mathrm{Fe}=28.294 ; \mathrm{Mn}=198 ; \mathrm{Zn}=$ 2.695; $\mathrm{Cu}=694 ; \mathrm{Ni}=280 ; \mathrm{Cd}=9 ; \mathrm{Cr}=804 ; \mathrm{Pb}=160$ (em $\left.\mathrm{mg} \mathrm{kg}^{-1}\right)$. A amostra para a análise química foi seca ao ar e à sombra, moída e passada em peneira com 2 mm de abertura de malha.

Para a contaminação do lodo de esgoto, porções desse material, equivalentes a $0,5 \mathrm{~kg}$ foram transferidas para sacos plásticos e receberam 0,140 , 
350 e $665 \mathrm{mg} \mathrm{kg}^{-1}$ de $\mathrm{Ni}$, na forma de $\mathrm{NiCl}_{2}$, para atingirem concentrações próximas e superiores aos permitidos pela CeтEsB (1999), que é de $420 \mathrm{mg} \mathrm{kg}^{-1}$ (base seca). Cada uma das contaminações, inclusive a porção que não recebeu o $\mathrm{NiCl}_{2}$, foram instaladas com quatro repetições e umedecidas a $70 \%$ da capacidade de retenção de água. Incubou-se por 60 dias nas condições da casa de vegetação com revolvimento periódico (semanal) para melhor homogeneização das amostras, a fim de facilitar as reações do íon com os constituintes do resíduo. No fim do período de incubação, nas porções de lodo de esgoto observaram-se concentrações de 329, 502, 746 e $1119 \mathrm{mg} \mathrm{kg}^{-1}$ de Ni total (UsEPA, 1986).

O experimento foi instalado em vasos, dispostos sob um delineamento experimental inteiramente casualizado com cinco tratamentos (4 doses de Ni no lodo de esgoto e 1 tratamentotestemunha, sem adição de lodo de esgoto e com fertilização mineral) em quatro repetições.

$\mathrm{Na}$ semeadura, o solo do tratamento testemunha recebeu, por vaso, $1,4 \mathrm{~g}$ de $\mathrm{N}$ (sulfato de amônio), 8,78 g de $\mathrm{P}_{2} \mathrm{O}_{5}$ (superfosfato simples) e 1,74 $\mathrm{g}$ de $\mathrm{K}_{2} \mathrm{O}$ (cloreto de potássio). Os demais tratamentos receberam, por vaso, $44,12 \mathrm{~g}$ de lodo de esgoto (equivalente a $10 \mathrm{t} \mathrm{ha}^{-1}$, base seca) com as diferentes contaminações de $\mathrm{Ni}$ para cada tratamento, $0,95 \mathrm{~g}$ de $\mathrm{N}$ (sulfato de amônio), 2,25 $\mathrm{g} \mathrm{P}_{2} \mathrm{O}_{5}$ (superfosfato simples) e 1,31 g de $\mathrm{K}_{2} \mathrm{O}$ (cloreto de potássio). As quantidades de fertilizante mineral foram aplicadas de modo que igualasse o total de NPK contido no lodo de esgoto em relação à colocada como fertilizante mineral no tratamento-testemunha. Os solos adubados foram transferidos para os vasos com $10 \mathrm{~L}(9,3 \mathrm{~kg}$ de TFSA) de capacidade e irrigados com água destilada até atingir $70 \%$ da capacidade de retenção, e ainda, receberam $60 \mathrm{~mL}$ de solução de micronutrientes $(57,6$ $\mathrm{mg} \mathrm{H}_{3} \mathrm{BO}_{3} ; 118,2 \mathrm{mg} \mathrm{CuSO}_{4} 5 \mathrm{H}_{2} \mathrm{O} ; 184,8 \mathrm{mg} \mathrm{MnSO}_{4}$ $4 \mathrm{H}_{2} \mathrm{O} ; 5,4 \mathrm{mg} \mathrm{NaMoO}_{4} 2 \mathrm{H}_{2} \mathrm{O}$ e $\left.439,8 \mathrm{mg} \mathrm{ZnSO}_{4}\right)$ e 18 $\mathrm{mL}$ de solução de Fe EDTA $(0,45 \mathrm{~g}$ de sulfato ferroso heptaidratado; 0,60 $\mathrm{g}$ de EDTA e 1,44 $\mathrm{mL}$ de solução de $\mathrm{NaOH} 1 \mathrm{~mol} \mathrm{~L}^{-1}$ ) (Melo et al., 1998).

A planta-teste foi o sorgo granífero (Sorghum bicolor (L.) Moench), híbrido precoce da Família Safra Certa da Agroceres (IPUÃ, SP), de textura vítrea, coloração avermelhada sem tanino e com finalidade de uso na produção de grãos. As sementes (10 por vaso) foram semeadas diretamente nos vasos, três dias após a incorporação dos adubos. Quando as plântulas atingiram uma altura de aproximadamente $10 \mathrm{~cm}$ realizou-se desbaste, deixando-se duas plantas por vaso.

A adubação de cobertura foi realizada aos 60 dias após a adubação de semeadura, com 1,4 g de $\mathrm{N}$ (sulfato de amônio) e 1,69 $\mathrm{g}$ de $\mathrm{K}_{2} \mathrm{O}$ (cloreto de potássio) no tratamento testemunha, e de $0,94 \mathrm{~g}$ de $\mathrm{N}$ (sulfato de amônio) e $1,25 \mathrm{~g}$ de $\mathrm{K}_{2} \mathrm{O}$ (cloreto de potássio), por vaso, nos tratamentos que receberam lodo de esgoto.

Amostras de solo foram obtidas logo após a instalação do experimento - 0 dia após a incorporação dos respectivos adubos (d.a.i.) e no seu final (128 d.a.i.) - com o auxílio de um tubo de PVC com $1 / 2$ polegada de diâmetro. Esse tubo foi inserido em três pontos de cada vaso (tratamento) até o fundo. As três sub-amostras (três pontos) de cada vaso foram homogeneizadas para formar a amostra representativa do vaso.

As amostras de solo para fins de análise química foram secas ao ar, destorroadas, passadas em peneira com $2 \mathrm{~mm}$ de abertura de malha e analisadas com relação ao teor de $\mathrm{Ni}$ "total" mediante a digestão com $\mathrm{HNO}_{3}+\mathrm{H}_{2} \mathrm{O}_{2}+\mathrm{HCl}$ (USEPA, 1986). Os teores disponíveis foram obtidos por meio do uso dos extratores $\mathrm{HCl}$ 0,1 $\mathrm{mol} \mathrm{L}^{-1}$ (PAGE et al., 1982), DTPA a pH 7,3 (Lindsay e Norvell, 1978), Mehlich 1 (Delfelipo e Ribeiro, 1981), Mehlich 3 (Mehlich, 1984), e o $\mathrm{Na}_{2}$ EDTA 0,0005 $\mathrm{M}+\mathrm{CaCl}_{2}$ 0,01M (BROwN et al., 1971). Em todos os métodos de extração de $\mathrm{Ni}$, realizou-se agitação da amostra de terra com a solução extratora, extração, filtração e posterior leitura no espectrofotômetro de absorção atômica.

As amostras de planta de sorgo foram coletadas no período de desmontagem (128 d.a.i.) do experimento separando todas as partes: folha, colmo, raiz e grãos. Esse material foi lavado com água de torneira, água destilada e deionizada. No caso das raízes, realizou-se lavagem prévia com solução de $\mathrm{HCl}$ $0,1 \mathrm{~mol} \mathrm{~L}^{-1}$. Após a lavagem, o material vegetal foi acondicionado em saco de papel, colocado em estufa de ventilação forçada sob temperatura de $60-70{ }^{\circ} \mathrm{C}$ até a obtenção de massa constante (Melo et al., 1998), determinando-se a quantidade de matéria seca das partes das plantas de sorgo (folha, colmo, raiz e grãos). Após a secagem, o material foi pesado e moído em moinho tipo Willey, dotado de peneira de 40 mesh. A produção de grãos foi expressa em massa com teor de umidade corrigido para $13 \%$. Nessas amostras, avaliou-se o teor de $\mathrm{Ni}$ através da digestão com $\mathrm{HNO}_{3}$ $+\mathrm{H}_{2} \mathrm{O}_{2}+\mathrm{HCl}$ (UsePA, 1986), e a leitura foi realizada no espectrofotômetro de absorção atômica.

Os resultados constantes das análises de solo foram submetidos à análise da variância pelo teste $\mathrm{F}$ em parcelas subdivididas (parcelas para tratamentos e sub-parcelas para épocas de amostragem) e, nos casos em que o teste $\mathrm{F}$ foi significativo, as médias foram comparadas pelo teste de Tukey a 5\% de probabilidade (BANZATO e KRONCA, 1992). Os coeficientes de correlação e análises de regressão também foram efetuados. 


\section{RESULTADOS E DISCUSSÃO}

A aplicação do lodo de esgoto contaminado com doses crescentes de Ni proporcionou aumento nos teores "total" e disponíveis de $\mathrm{Ni}$ no solo nas duas épocas de amostragens ( 0 e 128 d.a.i.), como pode ser observado na figura 1. Esses aumentos ocorreram de maneira linear, com exceção apenas do teor "total" de níquel na segunda amostragem, que foi quadrática, decorrentes das doses de níquel.
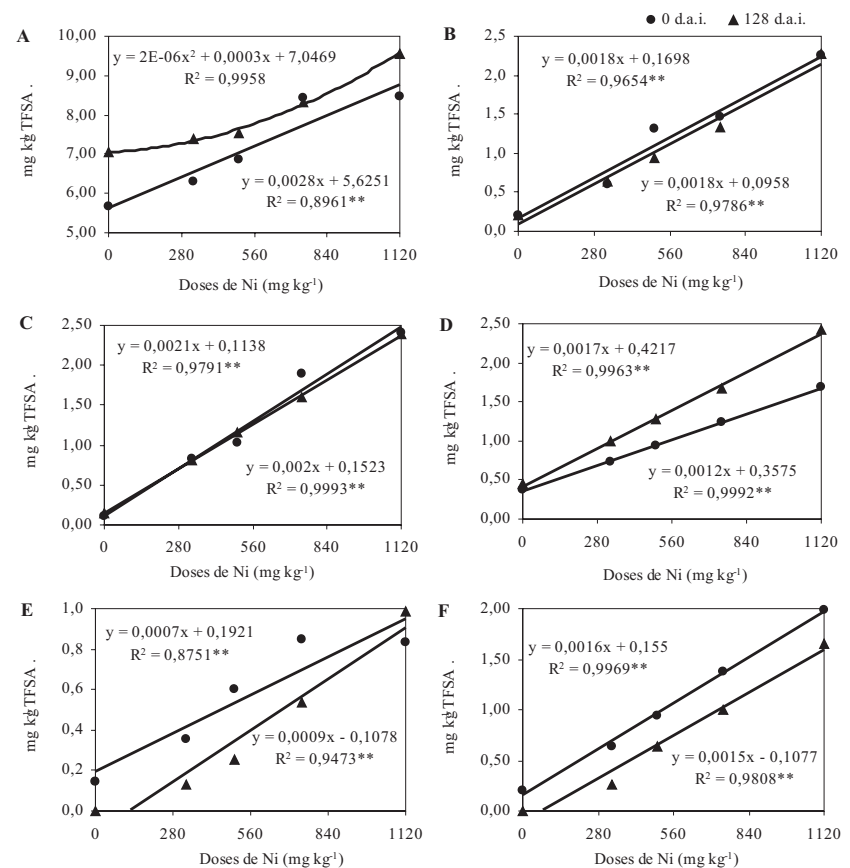

Figura 1. Regressões polinomiais dos teores "total" (A) e disponíveis de Ni extraídos pelos extratores $\mathrm{HCl} 0,1$ mol L ${ }^{-1}$ (B), Mehlich-1 (C), Mehlich-3 (D), DTPA (E) e $\mathrm{Na}_{2}$ EDTA (F) em solo submetido a cinco tratamentos (testemunha +4 doses de $\mathrm{Ni}$ no lodo de esgoto).

Os teores "totais" de níquel no solo foram determinados por meio da metodologia UsEPA (1986). Verificou-se, na época da instalação do experimento (0 d.a.i.), momento em que foram aplicados os respectivos adubos (lodo de esgoto e/ou adubos minerais), menores teores "totais"de Ni (Figura 1A) do que no fim do experimento (128 d.a.i.), evidenciando que parte do $\mathrm{Ni}$ não detectado no sistema solo-planta foi liberado após o período de crescimento e desenvolvimento das plantas de sorgo. Provavelmente, aos 0 d.a.i. existiam teores de níquel no solo, ligados às frações insolúveis que não foram detectados pelo método da UsEPA (1986). Concordando com as observações de REVOREDO (2005), que em alguns métodos apesar de denominarem o valor obtido como total, na verdade não o é. Assim, o método UsepA
(1986), cuja amostra de solo é tratada com $\mathrm{HNO}_{3}, \mathrm{HCl}$ e $\mathrm{H}_{2} \mathrm{O}_{2}$ concentrados e a quente, na realidade não determina o conteúdo total do metal pesado. Para que o teor total seja obtido é preciso conseguir a dissolução total da amostra, o que se consegue por uma complementação da digestão com HF a quente. E ainda, quando se coloca um metal pesado no solo pela adição de um resíduo, de um agroquímico ou simplesmente pela deposição atmosférica, se esse metal não for removido do ambiente por lixiviação ou pela remoção pelas culturas, seu teor no solo tende a aumentar. Às vezes, tal pode não ser detectado pelo tipo de metodologia usada na determinação do conteúdo total de metais (Melo et al., 2004).

Para o caso dos teores disponíveis de níquel no solo, verificou-se que os teores obtidos por meio dos extratores $\mathrm{HCl} 0,1 \mathrm{~mol} \mathrm{~L}^{-1}$, Mehlich-1, DTPA e $\mathrm{Na}_{2}$ EDTA (Figuras 1B, 1C, 1E, e 1F, respectivamente) na segunda amostragem (128 d.a.i.) foram menores. Essa diferença ocorreu devido à absorção desse elemento pelas plantas de sorgo, que era o esperado. Entretanto, o extrator Mehlich-3 (Figura 1D), detectou maiores teores de níquel nas amostras da segunda amostragem, da mesma maneira quando se empregou o método UsEPa (1986), para extrair os teores "totais". Assim, com hipótese semelhante, é possível que nas amostras da primeira amostragem, havia teores de níquel insolúveis com a aplicação da solução extratora do Mehlich-3, e que foram disponibilizados ao longo do cultivo das plantas de sorgo.

Realizando regressões polinomiais dos teores disponíveis de $\mathrm{Ni}$ com as doses de $\mathrm{Ni}$ dos tratamentos, verificou-se que a variação da disponibilidade desse metal ocorreu de maneira crescente e linear em função das doses de $\mathrm{Ni}$, obtendo um $R^{2}$ de 0,8751 a 0,9993 .

No estudo de comparação das quantidades extraídas de níquel por meio de extratores químicos (Tabela 1), verifica-se que as maiores quantidades extraídas de níquel ocorreram com o uso dos extratores Mehlich-1 e Mehlich-3, nas duas épocas de amostragens, vindo a seguir dos extratores $\mathrm{HCl} 0,1$ mol L ${ }^{-1}, \mathrm{Na}_{2}$ EDTA e DTPA, respectivamente. RIBEIROFilHo et al. (2001), estudando a disponibilidade de metais pesados em solo contaminado com materiais orgânicos, verificaram que o Mehlich-1 extraiu maiores quantidades de níquel que o DTPA. Oliveira e Mattiazzo (2001) e Oliveira (2002) também verificaram a maior capacidade de extração de metais pesados pela solução Mehlich-3 em relação à de DTPA.

Dentre os teores de níquel detectados pelos extratores, aqueles observados pelo extrator Mehlich3 foram os que mais se correlacionaram com os teores deste elemento absorvidos pelas plantas de sorgo 
$\left(0,89^{*}\right)$. Os demais também se correlacionaram, porém não foram muito expressivos. Oliveira e Mattiazzo (2001), estudando doses de aplicação lodo de esgoto no solo, verificaram que o extrator DTPA obteve maior correlação com os teores de níquel verificados no tecido vegetal das plantas de cana-de-açúcar $\left(0,98^{*}\right)$. Dessa maneira, é importante relatar que em cada situação, aplicação de lodo de esgoto com altas ou baixas concentrações de níquel, tipo de solo e cultura conduzida, existirá uma metodologia específica para quantificar os teores deste metal pesado no solo, e ainda, que se assemelha aos teores absorvidos pelas plantas.
Assim, em conseqüência dos teores de níquel encontrados no solo, em função dos tratamentos aplicados, nas quantidades desse metal pesado presente nas plantas de sorgo (Tabela 2), verificaramse o mesmo comportamento. As quantidades de níquel absorvidos pelas plantas variaram significativamente em função dos tratamentos. As plantas de sorgo absorveram $39,93 \% ; 101,16 \% ; 152,58 \%$ e $171,38 \%$ (tratamentos que receberam lodo de esgoto contendo $329,502,746$ e $1119 \mathrm{mg} \mathrm{kg}^{-1}$ de Ni respectivamente) de níquel a mais, em relação às plantas do tratamentotestemunha (sem adição de lodo de esgoto e com fertilização mineral).

Tabela 1. Teores disponíveis de níquel extraídos por quatro extratores, em solo submetido a cinco tratamentos (testemunha +4 doses de Ni no lodo de esgoto). Jaboticabal, Estado de São Paulo, 2004

\begin{tabular}{|c|c|c|c|c|c|}
\hline \multirow[t]{3}{*}{ Tratamentos * } & Mehlich-1 & $\mathrm{HCl} 0,1 \mathrm{~mol} \mathrm{~L}^{-1}$ & Mehlich-3 & \multirow[t]{2}{*}{ DTPA } & \multirow[t]{2}{*}{$\mathrm{Na}_{2}$ EDTA } \\
\hline & & & $\mathrm{mg} \mathrm{Ni} \mathrm{kg}{ }^{-1}$ & & \\
\hline & \multicolumn{4}{|c|}{0 dias após a incorporação } & \\
\hline Testemunha & $0,11 \mathrm{a}^{(1)}$ & 0,21 a & 0,38 a & 0,14 a & 0,20 a \\
\hline 329 & 0,83 a & $0,59 \mathrm{ab}$ & $0,94 \mathrm{a}$ & $0,36 \mathrm{~b}$ & 0,94 a \\
\hline 502 & 1,03 a & 1,31 a & $0,94 \mathrm{ab}$ & $0,60 \mathrm{~b}$ & $0,94 \mathrm{ab}$ \\
\hline 746 & 1,90 a & $1,47 \mathrm{~b}$ & $1,24 \mathrm{~b}$ & 0,85 с & $1,38 \mathrm{~b}$ \\
\hline 1119 & 2,41 a & $2,25 \mathrm{ab}$ & $1,69 \mathrm{c}$ & $0,83 \mathrm{~d}$ & $1,99 \mathrm{bc}$ \\
\hline C.V. $(\%)=$ & 19,5 & D.M.S. = & 0,39 & & \\
\hline
\end{tabular}

\begin{tabular}{lccccc} 
& \multicolumn{5}{c}{128 dias após a incorporação } \\
Testemunha & $0,15 \mathrm{~b}$ & $0,21 \mathrm{~b}$ & $0,46 \mathrm{a}$ & $\mathrm{nd}^{* *}$ & $\mathrm{nd}$ \\
329 & $0,81 \mathrm{~b}$ & $0,65 \mathrm{c}$ & $0,99 \mathrm{a}$ & $0,13 \mathrm{~d}$ & $0,27 \mathrm{~d}$ \\
502 & $1,16 \mathrm{a}$ & $0,95 \mathrm{~b}$ & $1,27 \mathrm{a}$ & $0,25 \mathrm{~d}$ & $0,63 \mathrm{c}$ \\
746 & $1,59 \mathrm{a}$ & $1,34 \mathrm{~b}$ & $1,67 \mathrm{a}$ & $0,54 \mathrm{~d}$ & $1,00 \mathrm{c}$ \\
1119 & $2,39 \mathrm{a}$ & $2,28 \mathrm{a}$ & $2,43 \mathrm{a}$ & $0,99 \mathrm{c}$ & $1,65 \mathrm{~b}$ \\
\hline C.V. $(\%)=$ & & D.M.S. $=$ & 0,16 & &
\end{tabular}

* As letras comparam apenas as médias dentro da mesma linha. Médias seguidas de pelo menos uma mesma letra não diferem entre si, pelo teste de Tukey a $5 \%$ de probabilidade. ${ }^{* *}$ nd: não detectado pelo método.

Segundo AdRiAno (1986), o teor de Ni na matéria seca de plantas varia de 0,1 a $5 \mathrm{mg} \mathrm{kg}^{-1}$, dependendo da espécie, parte da planta, estágio fenológico, conteúdo no solo, acidez do solo, entre outros fatores. Os teores verificados na matéria seca das plantas de sorgo neste experimento $\left(6,10\right.$ a $\left.16,31 \mathrm{mg} \mathrm{kg}^{-1}\right)$ ultrapassaram essa faixa. Porém, não houve qualquer sintoma de toxicidade pelo níquel nas plantas, mesmo aplicando $1.119 \mathrm{mg} \mathrm{kg}$ ${ }_{1}^{1}$ de Ni via lodo de esgoto. Para PAiva (2000), a toxidez de Ni se expressa quando sua concentração na matéria seca das plantas é maior que $50 \mathrm{mg} \mathrm{kg}^{-1}$, à exceção das espécies acumuladoras (grande tolerância) e hiperacumuladoras.

Analisando as quantidades de níquel presente nas partes das plantas de sorgo (folha, colmo, raiz e grão) apresentadas na Tabela 2, verifica-se que as quantidades desse metal se localizam em maior parte na raiz, vindo a seguir, no grão, na folha e no colmo. O comportamento das concentrações nas diversas partes da planta acompanhou os teores totais presente dessa planta, com exceção apenas das folhas, em que ocorreu diminuição da concentração presente em seu tecido, conforme se aumentavam as doses de Ni. Aplicando doses de biossólido de $60 \mathrm{t} \mathrm{ha}^{-1}$, WANG et al. (1997) relataram que o acúmulo de níquel em plantas de trigo foi maior nas folhas e nos colmos do que nos grãos. Em plantas de feijão, BOARETO et al. (1992) observaram teores de $7,2 \mathrm{mg} \mathrm{kg}^{-1}$ de Ni nos grãos, para aplicações de doses de biossólido em torno de $10 \mathrm{t} \mathrm{ha}^{-1}$, contra $0,9 \mathrm{mg} \mathrm{kg}^{-1}$ no tratamento-testemunha (adubação mineral). Para Melo et al. (2004), o metal pesado $\mathrm{Ni}$, em plantas de milho, tende a se acumular nas folhas e grãos, apresentando como teor crítico na matéria seca $11,0 \mathrm{mg}$ $\mathrm{kg}^{-1}$, mas têm sido relatados trabalhos que revelam teores de Ni entre 0,22 e $0,34 \mathrm{mg} \mathrm{kg}^{-1}$ para grãos de milho cultivado em solos não contaminados e teores entre 1,6 e 5,2 $\mathrm{mg} \mathrm{kg}^{-1}$ para a matéria seca de milho cultivado em solos que receberam lodo de esgoto (REIS, 2002). 
Tabela 2. Teores de níquel e quantidades de matéria seca (M.S.) em plantas de sorgo cultivadas em solo submetido a cinco tratamentos (testemunha +4 doses de Ni no lodo de esgoto). Jaboticabal, Estado de São Paulo, 2004

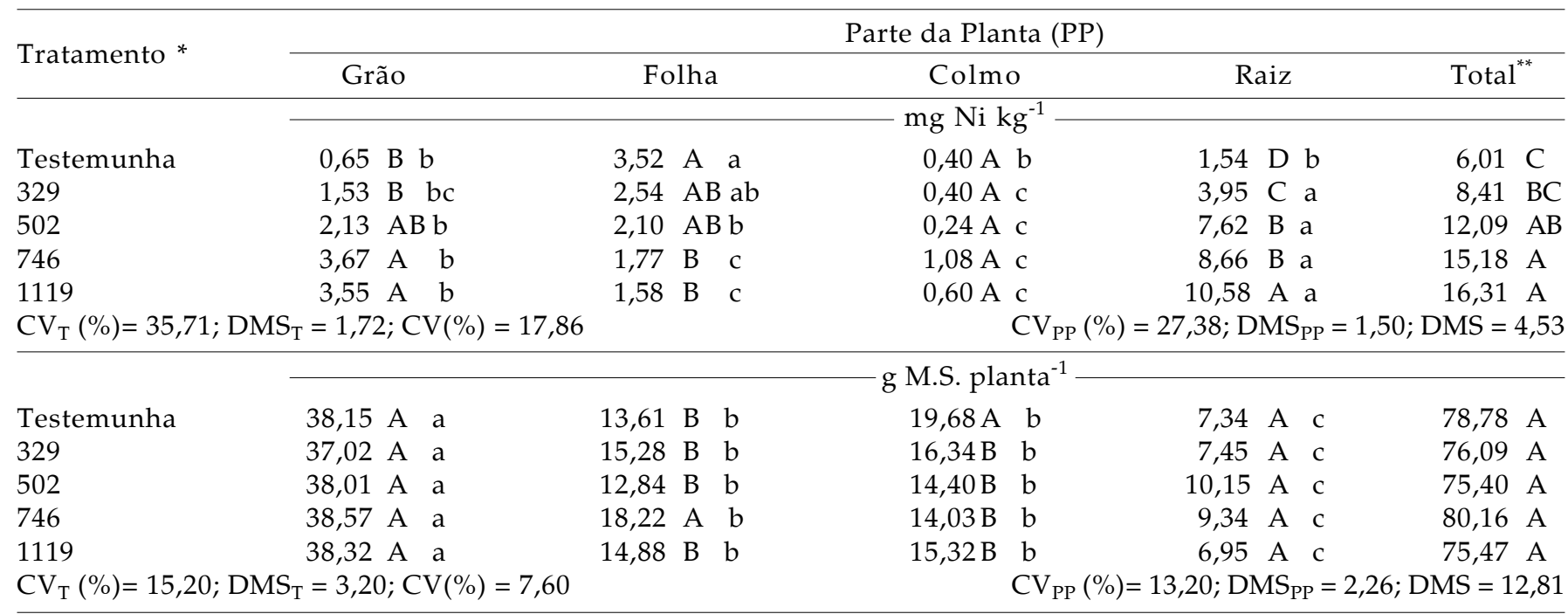

* Para as partes da planta, as letras maiúsculas comparam as médias dentro da mesma coluna e as minúsculas comparam as médias dentro da mesma linha. ${ }^{* *}$ Para os valores totais da planta, as letras maiúsculas comparam as médias dentro da mesma coluna. Médias seguidas de pelo menos uma mesma letra não diferem entre si, pelo teste de Tukey a $5 \%$ de probabilidade.

Nas quantidades de matéria seca total (Tabela 2) e na produção total de grãos de sorgo não se verificaram diferenças significativas em relação aos tratamentos aplicados. A média geral de matéria seca total foi de 77,18 g planta $^{-1}$ e para a produção de grãos (13\% de umidade), de 43,01 $\mathrm{g}_{\text {planta }}{ }^{-1}$. Analisando as quantidades de matéria seca nas partes das plantas de sorgo (Tabela 2), observa-se que, para as raízes e os grãos, não se detectou diferença estatística com relação aos tratamentos. Apenas a produção de matéria seca de folhas e colmos foram afetados pelo tratamento. $\mathrm{O}$ tratamento que recebeu $746 \mathrm{mg} \mathrm{kg}^{-1}$ de níquel via lodo de esgoto produziu mais matéria seca de folhas que os demais, enquanto no tratamento-testemunha, verificouse a maior quantidade de matéria seca de colmo.

\section{CONCLUSÕES}

1. A aplicação de lodo de esgoto contaminado com doses crescentes de níquel resultou em aumentos proporcionais nos teores "total" e disponíveis de níquel no solo.

2. Com os extratores Mehlich-1 e Mehlich-3 foram extraídos os maiores teores de níquel em solo tratado com lodo de esgoto.

3. O extrator Mehlich-3 foi o qual mais se correlacionou com as quantidades de níquel presentes nas plantas de sorgo.

4. A adição de 329, 502, 746 e $1.119 \mathrm{mg} \mathrm{kg}^{-1}$ de níquel, via lodo de esgoto, no solo, promoveu um aumento na absorção desse metal pesado pelas plantas de sorgo em $39,93 \% ; 101,16 \% ; 152,58 \%$ e $171,38 \%$.

\section{AGRADECIMENTOS}

Os autores agradecem à FAPESP, pelo suporte financeiro, e à CAPES, pela bolsa de estudo concedida ao primeiro autor.

\section{REFERÊNCIAS}

ABREU, C.A.; ABREU, M.F.; RAIJ, B. van; SANTOS, W.R. Comparação de métodos de análise para avaliar a disponibilidade de metais pesados em solos. Revista Brasileira de Ciência do Solo, Campinas, v.19, p.463-468, 1995.

ABREU, C.A. de; ABREU, M.F. de; SOARES, L.H.; ANDRADE, J.C. The effects of the DTPA extraction conditions on the determination of micronutrients in Brazilian soils. Communications in Soil Science and Plant Analysis, Cidade, v.28, p.1-11, 1997.

ADRIANO, D.C. Trace elements in the terrestrial environment. New York: Springer-Verlag, 1986. 533p.

ANJOS, A.R.M. Lixiviação de espécies químicas em latossolos sucessivamente tratados com biossólido e disponibilidade de metais pesados para plantas de milho. 1999. $191 \mathrm{f}$. Tese (Doutorado) - Escola Superior de Agricultura "Luiz de Queiroz", Universidade de São Paulo, Piracicaba.

BANZATTO, D. A.; KRONKA, S. N. Experimentação agrícola. 2.ed. Jaboticabal: FUNEP, 1992. p.43-51; 175-188. 
BERTONCINI, E.I. Mobilidade de metais pesados em solos tratados com lodo de esgoto. 1997. 90f. Dissertação (Mestrado) - Escola Superior de Agricultura "Luiz de Queiroz", Universidade de São Paulo. Piracicaba.

BOARETO, A.E.; MURUAKA, T.; NAKAGAWA, J.; CHITOLINA, J.C. Níquel e cádmio em grãos de feijão produzidos em solo adubado com lodo de esgoto. In: REUNIÃO BRASILEIRA DE FERTILIZADE DO SOLO E NUTRIÇÃO DE PLANTAS, 20., Piracicaba, 1992. Adubação, produtividade, ecologia: Anais, Piracicaba: SBCS, 1992. p.100-401.

BROWN, A L.; QUICK, J.; EDDINGS, J.L. A comparison of analytical methods for soil zinc. Soil Science Society of América, Madison, v.35, p.105-107, 1971.

CANTARELLA, H.; RAIJ, B. van; QUAGGIO, J.A. Situação da análise de solo e planta no Brasil. In: REUNIÃO BRASILEIRA DE FERTILIDADE DO SOLO E NUTRIÇÃO DE PLANTAS, 21., 1994, Petrolina. Fertilizantes: insumo básico para agricultura e combate à fome. Anais... Petrolina: EMBRAPA, CPATSA; SBCS; 1995. p.9-33.

CETESB. Aplicação de lodos de sistemas de tratamento biológico em áreas agrícolas - critérios para projeto e operação. São Paulo, 1999. p.4.230.(Manual Técnico)

CHANG, A.C.; HINESLY, T.D.; DONER, H.E.; DOWDY, R.H.; RYAN, J.A. Effects of long term sludge application on accumulation of trace elements by crops. In: PAGE, A.L.; LOGAN, T.J.; RYAN, J.A. Land application of sludge-food chain implications. Chelsea: Lewis Publisher, 1987. cap.4, p.53-66.

DEFELIPO, B. V.; RIBEIRO, A C. Análise química de solo: metodologia. Viçosa: Universidade Federal de Viçosa, 1981. 17p. (Boletim de Extensão, 29)

HOODA, P.S.; ALLOWAY, B.J. The plant availability and DTPA extractability of trace metals in sludge-amended soils. Science of the Total Environment, Amsterdam, v.149, p.39-51, 1993.

LINDSAY, W.L.; NORVELL, W.A. Development of DTPA soil test for zinc, iron, manganese and copper. Soil Science Society of America Journal, Madison, v.42, p.421-428, 1978.

MEHLICH, A. Mehlich 3 soil test extractant: a modification of Mehlich 2 extractant. Communications in Soil Science and Plant Analysis, New York, v.15, p.1409-1416, 1984.

MELO,G.M.P.;MELO, V.P.;MELO,W.J.Metais pesados no ambiente decorrente da aplicação de lodo de esgoto em solo agrícola. 98p. Disponívelem:http://www.mma.gov.br/port/conama/processos /cbf6214/lodometal.pdf Acesso em 29/06/04.

MELO, W. J.; MELO, G.M.P.; BERTIPAGLIA, M.A.; MELO, V.P. Experimentação sob condições controladas. Jaboticabal: FUNEP, 1998. p.22-24, 27-31, 41-55, 65-80.

MULCHI, C.L.; ADAMU, C.A.; BELL, P.F.; CHANEY, R.L. Residual heavy metal concentrations in sludge-amended coastal plain soils: I. Comparason of extractants. Communications in Soil Science and Plant Analysis, New York, v.22, p.919-941, 1991.
OLIVEIRA, F.C. Disposição de lodo de esgoto e composto de lixo num Latossolo Vermelho-Amarelo cultivado com cana-deaçúcar. 2000. 247p. Tese (Doutorado) - Escola Superior de Agricultura "Luiz de Queiroz", Universidade de São Paulo, Piracicaba.

OLIVEIRA, F.C.; MATTIAZZO, M.E. Mobilidade de metais pesados em um Latossolo amarelo distrófico tratado com lodo de esgoto e cultivado com cana-de-açúcar. Scientia Agrícola, Piracicaba, v.58, n.4, p.807-812, 2001.

OLIVEIRA, R.C.; CAMPOS, M.L.; SILVEIRA, M.L.A.; GUILHERME, L.R.G.; MARQUES, J.J.G.S.M.; CURI, N. Arsênio em solos do cerrado. In: FERTBIO 2002. Rio de Janeiro, UFRRJ, SBCS, SBM, 2002. CD Rom.

PAGE, A.L.; LOGAN, T.J.; RYAN, J.A. Land application of sludge: food chain implications. Chelsea: Lewis Publishers, 1987, 168p.

PAGE, A.L.; MILLER, R.H.; KEENEY, D.F. Methods of soil analysis. 2.ed. Madison: ASA, SSSA, 1982. 1159p.

PAIVA, H.N. Toxidez de Cd, Ni, Pb e Zn em mudas de cedro (Cedrela fissilis Vell.) e ipê roxo (Tabebuia impertiginosa (Mart.) Stand1.). 2000. 283 p. Tese (Doutorado) - Universidade Federal de Lavras, Lavras.

RAIJ, B. van; CANTARELLA, H.; QUAGGIO, J.A.; FURLANI, A.M.C. Recomendações de adubação e calagem para o Estado de São Paulo. 2.ed. revisada e atualizada. Campinas: Instituto Agronômico/Fundação IAC, 1997. p.66-67.

RAIJ, B. van; QUAGGIO, J.A.; CANTARELLA, H.; FERREIRA, M.E.; LOPES, AS.; BATAGLIA, O.C. Análise química do solo para fins de fertilidade. Campinas: Fundação Cargill, 1987.

REIS, T.C. Distribuição e biodisponibilidade do níquel aplicado ao solo como $\mathrm{NiCl}_{2}$ e lodo de esgoto. 2002. 118f. Tese (Doutorado) - Escola Superior de Agricultura "Luiz de Queiroz", Universidade de São Paulo, Piracicaba.

REVOREDO, M.D. Atributos químicos e bioquímicos de um latossolo tratado com lodo de esgoto contaminado com níquel e cultivado com sorgo. 2005. 88 f. Dissertação (Mestrado) Faculdade de Ciências Agrárias e Veterinárias, Universidade Estadual Paulista, Jaboticabal.

RIBEIRO-FILHO, M.R.; SIQUEIRA, J.O.; CURI, N.;SIMÃO, J.B.P. Fracionamento e biodisponibilidade de metais pesados em solo contaminado, incubado com materiais orgânicos e inorgânicos. Revista Brasileira de Ciência do Solo, Viçosa, v.25, p.495-507, 2001.

SIMONETE, M.A.; KIEHL, J.C. Extração e fitodisponibilidade de metais em resposta à adição de lodo de esgoto no solo. Scientia Agrícola. Piracicaba, v.59, p.555-563, 2002.

USEPA Standards for the use and disposal of sewage sludge. Washington: EPA, 1986 (Code of Federal Regulations 40 CRF Part 503)

WANG, P.; QU, E.; LI, Z.; SHUMAN, L.M. Fractions and availability of nickel in loessial soil amended with sewage sludge. Journal of Environmental Quality, Madison, v.26, p.795-801, 1997. 